\title{
Natural Substances for Prevention of Skin Photoaging: Screening Systems in the Development of Sunscreen and Rejuvenation Cosmetics
}

\author{
Vladimir Kostyuk, Alla Potapovich,, Ahmed R. Albuhaydar, , Wolfgang Mayer, \\ Chiara De Luca, and Liudmila Korkina ${ }^{3}$
}

\begin{abstract}
Solar broadband UV irradiation is commonly regarded as a major causative reason for cutaneous photoaging. The pro-aging molecular pathways and cellular targets affected by UVA+UVB light in human skin have been extensively investigated. Notwithstanding growing knowledge in mechanisms of photoaging, research and development of clinically efficient, nontoxic, and sustainable topical preparations providing full physical, chemical, and biological photoprotection still remain a great challenge for pharmaceutical and cosmetic industries. In this study, we are proposing a panel of the in vitro methods for preselection of natural photoprotective substances with high photostability and low phototoxicity able of absorbing a broadband UVA+UVB irradiation (physical sunscreen), reducing UV-related overproduction of free radicals and loss of endogenous antioxidants (chemical protection), and attenuating UV-induced cytotoxicity and immune and metabolic responses (biological protection) in primary human epidermal keratinocytes and immortalized human keratinocyte cultures. Our data showed that secondary metabolites biosynthesized in plant cells in response to UV irradiation, such as phenylpropanoids and their glycosylated metabolites, aglycons and glycosylated flavonoids, and leontopodic acids, hold the best promise for complete natural topical prevention of photoaging and rejuvenation of photoaged skin. Meristem plant cell cultures elicited by solar simulating UV could be the most environmentally sustainable biotechnological source of polyphenols with combined photoprotective and antiaging properties.
\end{abstract}

Keywords: human keratinocytes, photostability, photo-chemotoxicity, plant polyphenols, skin photoaging, solar UVA+UVB, broadband sunscreens

\section{Introduction}

$\mathbf{P}$ HOTOAGING REMAins among unsolved problems of modern dermatology with unmet as yet therapeutic needs. ${ }^{1}$ Comprehensive meta-analysis of publications ${ }^{2}$ dedicated to mechanisms and pathogenesis-based treatments of photoaging has revealed three major approaches behind its current management: strategies to prevent UV interaction with skin components (physical and chemical protection) or/ and to attenuate UV-related damage (biological protection) or to reverse existing symptoms of photo-aging (repair and regeneration protocols). The conclusions of the analysis were that the photoprotection approach still represents the best current management option.

Higher plants and lower eukaryotes, such as marine micro/ macroalgae, corals, jellyfish, and so on, have evolved biosynthesis of secondary metabolites, which do not participate directly in their growth, division, and propagation, but are essential for signal transduction, for coordination of cell functions, and for defense and adaptation to continuously

\footnotetext{
${ }^{1}$ Department of Biology, Byelorussian State University, Minsk, Belarus.

${ }^{2}$ MEDENA AG, Affoltern-am-Albis (ZH), Switzerland.

${ }^{3}$ Centre for Innovative Biotechnological Investigations NANOLAB (CIBI-NANOLAB), Moscow, Russia.

(C) Vladimir Kostyuk et al., 2018; Published by Mary Ann Liebert, Inc. This Open Access article is distributed under the terms of the Creative Commons Attribution Noncommercial License (http://creativecommons.org/licenses/by-nc/4.0/) which permits any noncommercial use, distribution, and reproduction in any medium, provided the original author(s) and the source are cited.
} 
changing environmental conditions (to co-called biotic and abiotic stresses). ${ }^{3-5}$ A great majority of secondary metabolites can interact with solar UV irradiation although in different manner.

(1) Some of them, mainly polyphenols like phenylpropanoids and their glycosides, as well as bioflavonoids, are synthesized in plant cells through phenylpropanoid pathway immediately upon exposure to UV. ${ }^{3,6}$ Having molecular structure consisting of condensed aromatic 5- and 6-carbon rings with multiple $\mathrm{OH}$ groups, they effectively absorb UVA+UVB (sunscreen properties) (Fig. 1, 5-10), although without promotion of further photochemical reactions; therefore, they have been considered safer than classical synthetic sunscreens, ${ }^{7}$ chemical structures of which are also aromatic polyphenols. ${ }^{8,9}$ Moreover, the presence of glycosyl moieties in secondary metabolites provides increased photostability hence many of the glycosylated metabolites are not susceptible to UVA destruction. ${ }^{10}$

(2) Other secondary metabolites (stilbenes, catechins, flavonoids, and terpenoids) preferably protect plant molecules and structures against damaging effects of reactive oxygen species (superoxide anion-radicals, hydroxyl radicals, peroxides, and singlet oxygen) formed upon UV reaction with organic matter in the presence of molecular oxygen (type II photoreactions). ${ }^{11,12}$

(3) In contrast, nitrogen-containing heterocycles (Fig. 1, 1-4) and terpenoids are photosensitizers, which use energy of UV, visible, or infrared solar irradiation to promote biologically important free radical-driven photochemical reactions, such as photosynthesis or terpenoid- and polyphenol-containing polymer synthesis. ${ }^{3}$

This UV-protecting system in plants and lower marine organisms resembles cutaneous photochemical barrier in humans consisting of photo screens (pheomelanin, melatonin, and proteins rich of aromatic amino acids $)^{13}$ and photosensitizers (eumelanin, porphyrins, flavins, hemoglobin, purins, and pyrimidines). ${ }^{14}$ This barrier efficacy depends on the photoprotector/photosensitizer balance that gradually deteriorate in aging or ailing human skin. ${ }^{13}$

Currently, plants and marine organisms are considered valuable sources of anti-photoaging and photoprotective compounds for the development of cosmeceutical and topical pharmaceutical products. ${ }^{5,12,15,16}$ However, up to now the use of natural secondary metabolites for human skin photoprotection is limited by their ability to diminish free radical and singlet oxygen-mediated damage to cells and extracellular matrix related to photochemical reactions. Total extracts of grown plant parts ${ }^{11,17}$ and whole marine organisms ${ }^{5}$ have been evaluated, and individual polyphenols belonging to phenylpropanoids or flavonoids with photoprotective properties were identified.

Secondary metabolites such as epicatechin and catechin from grape seeds have been proposed to stabilize common synthetic sunscreens through free radical scavenging mechanism. ${ }^{18}$ To phenolics possessing antioxidant and antiinflammatory properties have been recently attributed antiphotoaging and UV-induced carcinogenesis preventive effects of topical botanics like Polypodium leucotomos extract $\left(\right.$ Fernblock $\left.^{\circledR}\right),{ }^{19}$ propolis, plants, and lichens. ${ }^{15}$
1

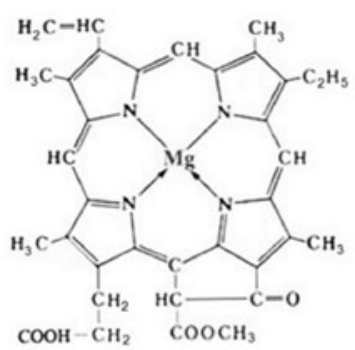

2<smiles>C1=NC=C2CNC(=N2)N1</smiles>

Purin

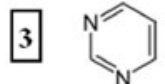

Pyrimidine
4

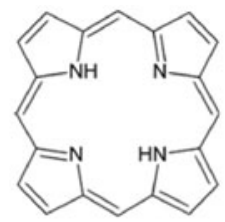

Porphyrin

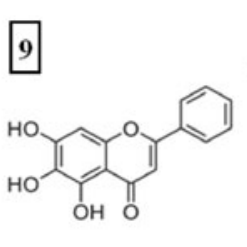

Baicalin

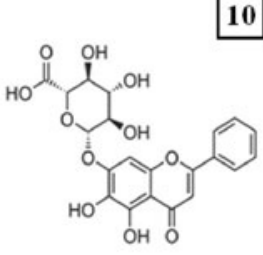

Baicalein

10
Chlorophyll

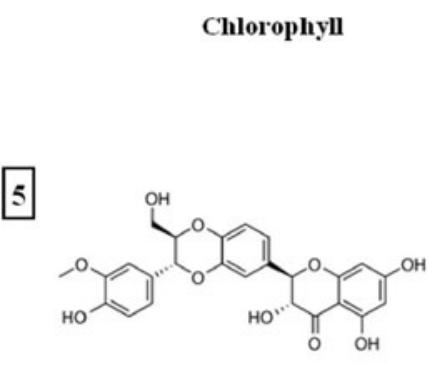

Silibinin

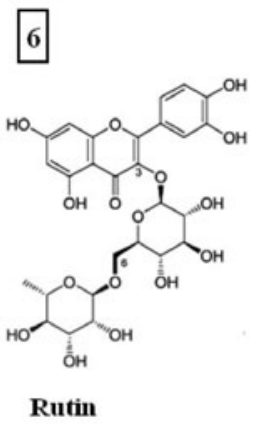

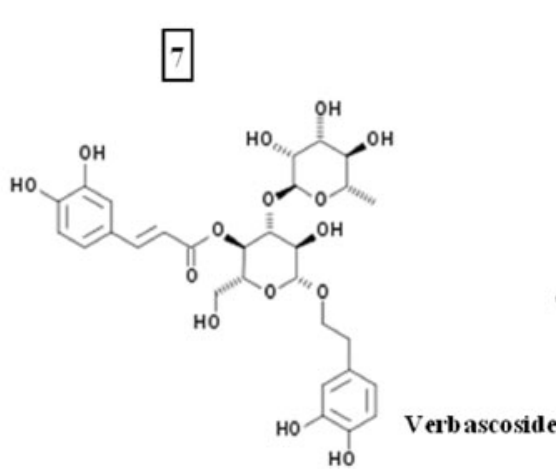

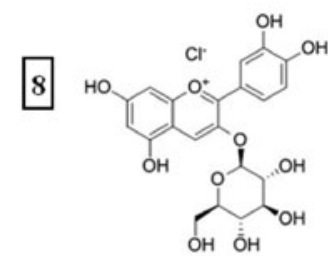

Cyanidin-3-O-glucoside

FIG. 1. Chemical structures of plant-derived secondary metabolites interacting with solar irradiation. 1-4, photosensitizers which absorb solar light energy and transform it into energy of chemical/biochemical reactions (anoxic type I or oxygen-dependent type II). 5-10, substances with mainly photoprotective (sunscreen) properties which absorb solar light energy and dissipate it in the forms of thermal, fluorescence/phosphorescence, or oscillation energy. 
When whole botanical extracts are used for topical photoprotection, there is a great risk of adverse photosensitizing effects of definite plant-derived secondary metabolites. ${ }^{20}$ It seems that secondary metabolites synthesized in plant cell cultures elicited by a broadband UV light could be the purest and most efficient photoprotectors, ${ }^{16}$ which could be active substances in preventive, sunscreen, or postsun topical products. $^{21}$

Theoretically, secondary plant metabolites could modify skin-UV interaction at several crucial points: (1) by absorption of UVA+UVB (screen action); (2) by inhibition of UV-induced free radical reactions in skin cells and extracellular matrix (scavenging and direct antioxidant chainbreaking effects); (3) by protection of skin surface lipid antioxidants, such as alpha-tocopherol, coenzyme Q10, and squalene (antioxidant rescue action); (4) by induction of endogenous antioxidant systems in keratinocytes and fibroblasts (indirect antioxidant effects); (5) by attenuation of inflammatory responses in cutaneous immune cells (keratinocytes/leukocytes/dendritic cells); (6) by modulation of excessive metabolic and proliferative UV-induced stress responses (anti-stress effects), and (7) by attenuation of UVrelated immune suppression (immunomodulation). ${ }^{20-27}$

In this study, we are proposing a panel of the in vitro methods for preselection of natural photoprotective substances with high photostability and low phototoxicity able of absorbing a broadband UVA+UVB irradiation (physical sunscreen), reducing UV-related overproduction of free radicals and loss of endogenous antioxidants (chemical protection), and attenuating UV-induced cytotoxicity and immune and metabolic responses (biological protection) in primary human epidermal keratinocytes and immortalized human keratinocyte cultures.

\section{Materials and Methods}

\section{Reagents and mediums}

Practically all solvents, salts, mediums, and reagents were from Sigma-Aldrich (Milan, Italy). In addition benzophenone3 , rutin, quercetin, trans-ferulic and chlorogenic acids, and silibinin were from Sigma-Aldrich. Acacetin, baicalein, chalcone, cyanidin chloride, chrysin, and (+)-taxifolin were purchased from Extrasynthese Co. (Lyon, France) and resveratrol from Biomol (Research Lab, Plymouth, MA). Verbascoside (>97\% purity) was isolated from meristem plant cells of Syringa vulgaris, and leontopodic acids ( $>98 \%$ purity) were from meristem plant cells of Leontopodium alpinum (IRB S.r.l., Altavilla Vicentina, Italy). Other reagents, primers, and antibodies are mentioned herein below in the appropriate subsections.

\section{Cell cultures and their exposure to UV and polyphenols}

For the evaluation of cytotoxicity of polyphenols/ benzophenone-3 and combined photo-cytotoxicity of UV and polyphenols, the immortalized human keratinocyte cell line HaCaT was used. The HaCaT cells were grown in the high-glucose Dulbecco's modified Eagle's medium (DMEM) supplemented with $10 \%$ heat-inactivated fetal calf serum, $100 \mathrm{U} / \mathrm{mL}$ penicillin, and $100 \mu \mathrm{g} / \mathrm{mL}$ streptomycin at $37^{\circ} \mathrm{C}$ in a humidified atmosphere containing $5 \% \mathrm{CO}_{2}$. The $\mathrm{HaCaT}$ cells were seeded in a 96-well plate at a density of $1 \times 10^{4}$ cells $/ \mathrm{mL}$ in a volume of $200 \mu \mathrm{L}$. When the confluence of cellular monolayer reached $60 \%-70 \%$, the cells were washed with phosphate-buffered saline, $\mathrm{pH} 7.4$ (PBS) and were irradiated 30 minutes either with higher energy UVB+UVA $\left(3+6 \mathrm{~J} / \mathrm{cm}^{2}\right)$ or with lower energy UVA+UVB $\left(2+4 \mathrm{~J} / \mathrm{cm}^{2}\right)$ in PBS with or without $50 \mu \mathrm{M}$ PPs (polyphenols). In both cases, higher energy irradiation (with the effluence $5 \mathrm{~mW} /$ $\mathrm{cm}^{2}$ ) and lower energy irradiation (with the effluence $2.5 \mathrm{~mW} / \mathrm{cm}^{2}$ ) corresponded to a midday summer solar irradiance. Full solar energy arriving at the surface (clear sky) is $\sim 1025 \mathrm{~W} / \mathrm{m}^{2}$. Since the percentage of UV radiation is $5 \%$, the corresponding energy is $51 \mathrm{~W} / \mathrm{m}^{2}$ or $\sim 5 \mathrm{~mW} / \mathrm{cm}^{2}$ ).

Multi-well plates with cell monolayer were irradiated without lid. In the preliminary experiments, we found that the temperature of PBS used as a medium for HaCaT cells was changed from $26.0^{\circ} \mathrm{C} \pm 0.1^{\circ} \mathrm{C}$ to $32.2^{\circ} \mathrm{C} \pm 0.3^{\circ} \mathrm{C}$ after 40 minute irradiation with higher energy UV. There were no significant PBS volume changes after a 40-minute irradiation.

Equal volumes of DMSO, a solvent for polyphenols and benzophenone, at $0.1 \%$ final concentration in the medium were added to control micro-wells. After irradiation the cells were thoroughly washed and incubated in fresh serum-free and polyphenol-free culture medium for 24 hours at $37^{\circ} \mathrm{C}$. Then, cell viability was determined by two methods as follows: by quantitative PrestoBlue Cell Viability Assay (Invitrogen Life Sciences, Paisley, United Kingdom) and by staining with fluorescence dyes acridine orange and ethidium bromide for microscopic visualization.

Primary cultures of normal human epidermal keratinocytes (NHEK) were obtained from skin biopsies of healthy volunteers $(n=6)$ after their informed consent. Primary cultures were grown in a $5 \% \mathrm{CO}_{2}$ humidified atmosphere in keratinocyte growth medium: DMEM and Ham's F12 (both from Lonza, Walkersville, MD) media (2:1 mixture) containing $10 \%$ fetal calf serum (Invitrogen), $0.18 \mathrm{mM}$ adenine and $0.4 \mu \mathrm{g} / \mathrm{mL}$ hydrocortisone (both from Calbiochem), $5 \mu \mathrm{g} / \mathrm{mL}$ insulin, $0.1 \mathrm{nM}$ cholera toxin, $2 \mathrm{nM}$ triiodothyronine, penicillin-streptomycin, $4 \mathrm{mM}$ glutamine (all from Sigma-Aldrich), and $10 \mathrm{ng} / \mathrm{mL}$ epidermal growth factor (Austral Biologicals). When NHEK cultures became subconfluent $(60 \%-80 \%)$ cells were transferred to keratinocyte growth medium containing growth factors (KGM-Gold; Lonza). For 24 hours before experiments, NHEK were starved in a medium deprived of all supplements.

NHEK monolayer was exposed to very low-dose UVA+UVB irradiation (time of irradiation 30 seconds, distance from cells $30 \mathrm{~cm}$, dose UVA $1.0 \mathrm{~J} / \mathrm{cm}^{2}+\mathrm{UVB} 0.1 \mathrm{~J} / \mathrm{cm}^{2}$ ) produced by Solar Simulator (Dermalight Vario with filter A2; Dr. Hoehnle AG, UV Technology, Planegg, Germany) with emission spectrum from $300 \mathrm{~nm}$ and emission peak at $375 \mathrm{~nm}$. The light effluence on the cell monolayer was $40 \mathrm{~mW} / \mathrm{cm}^{2}$.

In the experiments with the combined action of UV and polyphenols, to avoid their possible direct interaction, NHEK were preincubated with 10 or $50 \mu \mathrm{M}$ polyphenols for 30 minutes, thoroughly washed, and then exposed to UV light. The fresh medium containing 10 or $50 \mu \mathrm{M}$ polyphenols was added to NHEK for 24 hours postirradiation.

\section{Exposure of polyphenols to UV}

Changes in UVA+UVB protective capacity of polyphenols and benzophenone- 3 were assessed by UV-Visible 
spectrophotometry. The entire polyphenols absorption spectra between 220 and $600 \mathrm{~nm}$ were recorded before and after 1, 3, 20 , and 40 minutes irradiation of $50 \mu \mathrm{M}$ solutions of polyphenols in potassium phosphate buffer $(\mathrm{pH} 7.4)$ in $3.5 \mathrm{~cm}$ Petri dishes. The total UV doses (66\% UVA and 33\% UVB) were $0.15,0.45,3.0$, and $6.0 \mathrm{~J} / \mathrm{cm}^{2}$, respectively. Protection from UVB and UVA was calculated separately and expressed as SPF (UVB protection) and UVA/UVB ratio (UVA protection).

\section{UV-visible spectrophotometry of photoprotectors and SPF calculations}

Sunscreen capacity of potential photoprotectors was determined in vitro by ultraviolet spectrophotometry (Sayre et al. ${ }^{28}$ ) using a Mansur et al. ${ }^{29}$ Equation (1) for SPF calculations and an Equation (2) for determination of the UVA/UVB ratio:

$$
\mathrm{SPF}=\mathrm{CF} \times \sum_{290-320} \mathrm{EE}(\lambda) \times \mathrm{I}(\lambda) \times \mathrm{A}(\lambda),
$$

where $\mathrm{CF}$-correction factor $10, \mathrm{EE}(\lambda)$ - erythemogenic factor of UVB at wavelength $\lambda$, and the values of EE and I $(\lambda)$ are constants determined experimentally.

$$
\text { UVA } / U V B=\int_{321}^{400} A(\lambda) d \lambda / \int_{290}^{320} A(\lambda) d \lambda,
$$

where $\mathrm{A}(\lambda)$ is a monochromatic absorbance at wavelength $\lambda$.

The mixture of $50 \%$ isopropanol/50\% n-heptane was used as a solvent, and final concentrations of benzophenone- 3 or plant polyphenols were $0.02 \%$. The absorption spectra of samples in the range of $200-400 \mathrm{~nm}$ were obtained by a Varian UV/Vis spectrophotometer Cary 50 Scan in $1 \mathrm{~cm}$ quartz cuvette.

\section{Cyto-phototoxicity assays}

$\mathrm{HaCaT}$ cell proliferation and cellular viability were quantified by PrestoBlue Kit (Invitrogen) in plastic plates containing 96 micro-wells following the manufacturer's instructions. PrestoBlue Kit is based on the nonfluorescent light-blue reagent resazurin, which being absorbed by vital cells, is transformed into highly fluorescent compound of red color. After a 2 hours co-incubation of $\mathrm{HaCaT}$ cells with PrestoBlue reagent at $37^{\circ} \mathrm{C}$, fluorescence was excited at wavelength $535 \mathrm{~nm}$, and the emission peak at $615 \mathrm{~nm}$ was recorded by a Hitachi 580 microfluorimeter.

For fluorescence microscopy, the mixture of two vital fluorescence dyes acridine orange $(30 \mu \mathrm{g} / \mathrm{mL})$ and ethidium bromide $(30 \mu \mathrm{g} / \mathrm{mL})$ was added to micro-wells with cell monolayer. After 20 minutes of incubation at $37^{\circ} \mathrm{C}$, stained cells were visualized and photographed by an Axiovert 25 (Zeiss, Germany) fluorescence microscope equipped with a digital camera.

\section{mRNA isolation and quantitative real-time polymerase chain reaction assay}

Total RNA was isolated using the GenElute Mammalian Total RNA Kit (Sigma-Aldrich) and was reverse transcribed using the iScript cDNA Synthesis Kit (Bio-Rad, Hercules, CA) at $42^{\circ} \mathrm{C}$ for 30 minutes. cDNA was amplified with iQ SYBR Green Supermix (Bio-Rad) using the MiniOpticon Real-Time PCR Detection System (Bio-Rad).
Two housekeeping genes, ribosomal $18 \mathrm{~S}$ and $\beta$-actin, were chosen as reference. Fold changes were calculated according to Reference. ${ }^{30}$ The following primer sets were designed using Primer-BLAST (NCBI) and synthesized by Eurofins MWG Operon (Ebersberg, Germany): $\beta$-actin fwd $5^{\prime}$-AAA TCTGGCACCACACCTTCTAC-3'; $\beta$-actin rev 5'-ATAGC ACAGCCTGGATAGCAAC-3'; $18 S$ rRNA fwd 5'- TCCCC CAACTTCTTAGAGG-3'; $18 S$ rRNA rev 5'- GCTTATGA CCCGCACTTAC-3'; CYP1A1 frw:5'-CCTGGAGACCTTC CGGCACT-3'; CYP1A1 rev:5'-AGACACAACGCCCCTTG GGG-3'; CYP1B1 frw:5'-TGGTCTGTGAATCATGACCCA GTGA-3'; CYP1B1 rev:5'TCTTCGCCAATGCACCGCCT3'; ILI $\beta$ fwd:5'-TGGCTCATTTTCCCTCAAAAGTTG-3'; ILI $\beta$ rev:5'-AGAAATCGTGAAATCCGAAGTCAAG-3'; $I L-6$ fwd:5'-GTGTGAAAGCAGCAAAGAG-3'; IL-6 rev:5'CTCCAAAAGACCAGTGATG-3'; $I L-8$ frw:5'-GTCCTTG TTCCACTGTGCCT-3'; $I L-8$ fwd:5'-GTCCTTGTTCCACT GTGCCT-3'; IL-8 rev:5'-GCTTCCACATGTCCTCACAA3'; and $T N F \alpha$ fwd:5'- TCCTTCAGACACCCTCAACC-3'; $T N F \propto$ rev:5'- AGGCCCCAGTTTGAATTCTT-3'.

\section{Western blot assay}

To obtain whole cell extracts, NHEK were lysed with radioimmunoprecipitation assay (RIPA) buffer. Western blot was performed using polyclonal antibodies to phosphorylated p65 and actin (Cell Signaling Technology, Beverly, MA) as a control of protein loading.

\section{Statistical evaluation}

The evaluation was carried out by standard EXCEL program (Microsoft). Results are presented as mean $\pm S D$ of multiple (at least, three) independent experiments and repeated measurements within a single experiment. To evaluate the difference between experimental groups, two-tailed Student's $t$-test was applied, and $p$ values $<0.05$ were considered to be significant.

\section{Results}

\section{Plant polyphenols are effective screens for UVB and UVA solar simulating irradiation}

In the first set of experiments, we applied spectrophotometry method to distinguish and compare UVB and UVA absorption by classical sunscreen substance benzophenone-3 and several selected plant-derived polyphenolics having the phenylpropanoid, flavonoid, stilbene, and catechin chemical structure. SPF-B values were calculated for molecular and $\%$ concentrations, while protection from UVA was determined by the UVA/UVB ratio (Table 1). The data demonstrate that some of the polyphenols were similarly effective as UVB screens as benzophenone-3 (taxifolin, silibinin, cyanidin chloride, verbascoside, acacetin, kaempferol, quercetin, baicalein, and rutin). Several polyphenols were much more effective UVB screens (chalcone, resveratrol, leontopodic, and trans-ferulic acids). At the same time, epicatechin, chrysin, and morin absorb UVB less effectively than the positive control substance.

Regarding UVA absorption, benzophenone-3, epicatechin, chalcone, resveratrol, and trans-ferulic acid were weak screens for UVA although morin, rutin, kaempferol, quercetin, and baicalein absorb predominantly UVA. 
Table 1. Ultraviolet B and A Absorption by Classical Synthetic Sunscreen and Plant Polyphenols

\begin{tabular}{lrrr}
\hline Polyphenols & \multicolumn{1}{c}{$\begin{array}{c}S P F 1 \\
(250 \mu M)\end{array}$} & \multicolumn{1}{c}{$\begin{array}{c}\text { SPF2 } \\
(10 \%)\end{array}$} & $U V A / U V B$ \\
\hline Benzophenone-3 & $4.99 \pm 0.10$ & $8.75 \pm 0.12$ & 0.33 \\
Resveratrol & $11.98 \pm 0.11$ & $21.02 \pm 0.11$ & 0.25 \\
Leontopodic acids & $11.83 \pm 0.12$ & $6.79 \pm 0.12$ & 0.51 \\
Verbascoside & $8.25 \pm 0.09$ & $5.29 \pm 0.09$ & 0.59 \\
Chalcone & $8.15 \pm 0.14$ & $15.67 \pm 0.17$ & 0.32 \\
trans-Ferulic acid & $7.15 \pm 0.30$ & $14.74 \pm 0.60$ & 0.18 \\
Silibinin & $6.44 \pm 0.14$ & $5.34 \pm 0.16$ & 0.46 \\
Taxifolin & $6.38 \pm 0.12$ & $8.39 \pm 0.14$ & 0.46 \\
Rutin & $5.25 \pm 0.13$ & $3.44 \pm 0.16$ & 1.20 \\
Cyanidin chloride & $4.93 \pm 0.12$ & $6.11 \pm 0.15$ & 0.52 \\
Acacetin & $4.86 \pm 0.22$ & $6.85 \pm 0.19$ & 0.77 \\
Quercetin & $4.31 \pm 0.10$ & $5.71 \pm 0.12$ & 1.50 \\
Kaempferol & $4.0 \pm 0.15$ & $5.59 \pm 0.18$ & 1.11 \\
Baicalein & $3.65 \pm 0.12$ & $5.41 \pm 0.12$ & 1.14 \\
Morin & $2.63 \pm 0.08$ & $3.48 \pm 0.12$ & 1.70 \\
Chrysin & $1.62 \pm 0.07$ & $2.55 \pm 0.07$ & 0.96 \\
Epicatechin & $0.10 \pm 0.02$ & $0.14 \pm 0.04$ & 0.25 \\
\hline
\end{tabular}

\section{UVA plus UVB photostability of plant polyphenols}

Evaluating UV-visible absorption spectra of polyphenols, we observed clear-cut difference between stability of polyphenols to increasing doses of UV irradiation. For example, absorption spectrum of resveratrol changed dramatically, while that of verbascoside remained unchanged within the range of UV doses applied (Fig. 2). Quantification of polyphenol instability to UVA+UVB exposure showed that SPF-B values of some polyphenols (chalcone, chrysin, resveratrol, quercetin, trans-ferulic acid, and acacetin) and benzophenone- 3 dropped significantly and depended on UV doses related to the time of exposure (Table 2).

\section{Cytotoxicity versus cyto-phototoxicity and cyto-photoprotection of plant polyphenols}

Polyphenols effective as broad UV-band screens with significant UV-stability were chosen for further in vitro ex-

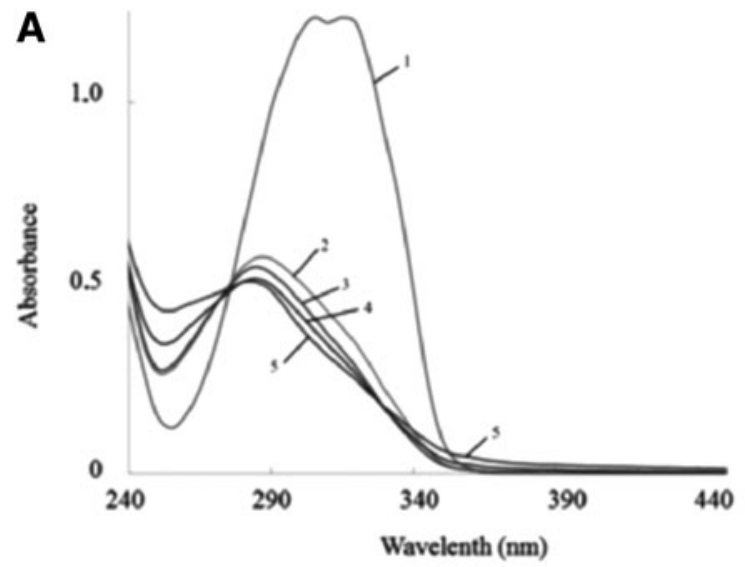

periments on $\mathrm{HaCaT}$ cell cultures. To evaluate possible connection between physical UVA+UVB protection and biological protection against UVA+UVB cytotoxicity, we compared data of UV transmission through the $4 \mathrm{~mm}$ thick layer containing $50 \mu \mathrm{M}$ polyphenol or benzophenone-3 solutions with cytotoxic UV effects on $\mathrm{HaCaT}$ cells irradiated under the same experimental conditions (Table 3 ). The comparison showed very close connection between physical and biological protection. Benzophenone-3 exerted the lowest physical and biological protection, while baicalein and verbascoside were highly cytoprotective and transmitted much less broadband UV light than benzophenone-3.

Several polyphenols, such as chalcone and resveratrol, remarkably induced UV photo-chemotoxicity in $\mathrm{HaCaT}$ cells exposed to a low-dose noncytotoxic solar simulated UVA+UVB $\left(2+4 \mathrm{~J} / \mathrm{cm}^{2}\right)$ irradiation in a time-dependent manner (Fig. 3A). Fluorescent microphotographs of cells stained with acridine orange/ethidium bromide demonstrate that UV irradiation alone did not induce cell death up to 24 hours postirradiation. However, the presence of chalcone sharply and time-dependently increased cell death by apoptosis, while the combination UV+resveratrol drastically increased cell death by necrosis. Quantification of photochemotoxic effects of polyphenols using PrestoBlue assay revealed that taxifolin, rutin, silibinin, verbascoside, and baicalein did not possess this kind of cytotoxicity. In contrast, benzophenone-3, trans-ferulic acid, quercetin, and cyanidin chloride exerted slight but statistically significant chemo-phototoxicity. The worst inducers of cell death were resveratrol and chalcone (Fig. 3B). Only chalcone was cytotoxic to $\mathrm{HaCaT}$ cells at $50 \mu \mathrm{M}$ concentration (Fig. 3B, third column).

\section{Plant polyphenols inhibit inflammatory and metabolic responses to solar simulated UV irradiation in normal primary human epidermal keratinocytes}

Since molecular responses to external stresses, including $\mathrm{UV}$ of HaCaT and primary human keratinocytes, are significantly different, ${ }^{22}$ we used primary NHEK cultures to evaluate combined effects of very low stimulatory doses of

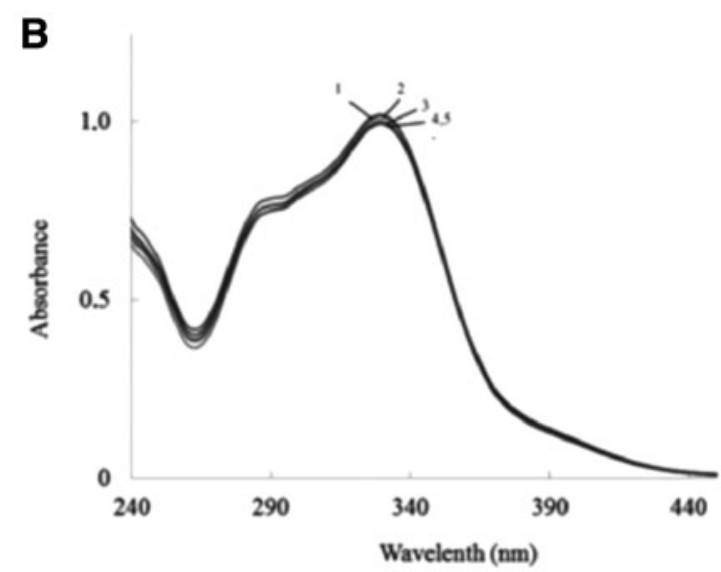

FIG. 2. Photostability of polyphenols. UV-visible absorption spectra of $50 \mu \mathrm{mol} / \mathrm{L}$ resveratrol (A) and verbascoside (B) in $0.1 \mathrm{M}$ potassium phosphate buffer ( $\mathrm{pH} 7.4$ ) recorded (1) before and (2-5) 1, 3, 20, and 40 minutes after solar-simulated irradiation $\left(\mathrm{UVA} / \mathrm{UVB}=2 / 1\right.$, irradiance $\left.25 \mathrm{~W} / \mathrm{m}^{2}\right)$. 
Table 2. Effect of Solar Simulating UV Irradiation of SPF Values of Sunscreens (Photostability of Sunscreens)

\begin{tabular}{|c|c|c|c|c|c|}
\hline \multirow[b]{2}{*}{ Polyphenols } & \multicolumn{5}{|c|}{$U V(66 \% U V A$ and $33 \% U V B) \mathrm{J} / \mathrm{cm}^{2}$} \\
\hline & 0 & 0.15 & 0.45 & 3.0 & 6.0 \\
\hline Benzophenone-3 & $4.99 \pm 0.10$ & $4.38 \pm 0.10 *$ & $4.18 \pm 0.10 *$ & $4.20 \pm 0.10 *$ & $4.19 \pm 0.10^{*}$ \\
\hline Verbascoside & $8.25 \pm 0.09$ & N/D & N/D & $8.23 \pm 0.12$ & $8.26 \pm 0.10$ \\
\hline Taxifolin & $6.38 \pm 0.12$ & N/D & N/D & $6.38 \pm 0.12$ & $6.39 \pm 0.12$ \\
\hline Rutin & $5.25 \pm 0.13$ & N/D & $\mathrm{N} / \mathrm{D}$ & $5.25 \pm 0.13$ & $5.25 \pm 0.13$ \\
\hline Silibinin & $6.44 \pm 0.14$ & $6.41 \pm 0.14$ & $6.46 \pm 0.14$ & $6.45 \pm 0.14$ & $6.44 \pm 0.14$ \\
\hline Cyanidin & $4.93 \pm 0.12$ & $4.91 \pm 0.12$ & $4.91 \pm 0.12$ & $4.94 \pm 0.12$ & $4.93 \pm 0.12$ \\
\hline Kaempferol & $4.0 \pm 0.15$ & N/D & $3.97 \pm 0.15$ & $4.02 \pm 0.15$ & $4.1 \pm 0.15$ \\
\hline Baicalein & $3.68 \pm 0.15$ & $3.63 \pm 0.12$ & $3.62 \pm 0.13$ & $3.69 \pm 0.12$ & $3.79 \pm 0.12$ \\
\hline Morin & $2.63 \pm 0.08$ & N/D & N/D & $2.62 \pm 0.08$ & $2.78 \pm 0.08$ \\
\hline Epicatechin & $0.10 \pm 0.02$ & N/D & N/D & $0.10 \pm 0.02$ & $0.10 \pm 0.02$ \\
\hline Leontopodic acid & $11.83 \pm 0.1$ & $11.62 \pm 0.22$ & $11.48 \pm 0.2$ & $10.64 \pm 0.2 *$ & $10.1 \pm 0.12 *$ \\
\hline Quercetin & $4.31 \pm 0.10$ & $3.95 \pm 0.20 *$ & $3.79 \pm 0.20 *$ & $3.48 \pm 0.20 *$ & $3.16 \pm 0.20 * *$ \\
\hline Resveratrol & $11.98 \pm 0.1$ & $4.81 \pm 0.20 * *$ & $4.25 \pm 0.20 * *$ & $4.93 \pm 0.16^{* *}$ & $4.63 \pm 0.10 * *$ \\
\hline Chalcone & $8.15 \pm 0.14$ & $3.49 \pm 0.20 * *$ & $3.33 \pm 0.20 * *$ & $3.09 \pm 0.23 * *$ & $2.88 \pm 0.24 * *$ \\
\hline trans-Ferulic acid & $7.34 \pm 0.18$ & $5.34 \pm 0.09 * *$ & $3.91 \pm 0.11 * *$ & $3.61 \pm 0.13 * *$ & $3.74 \pm 0.17 * *$ \\
\hline Acacetin & $4.77 \pm 0.10$ & $3.61 \pm 0.90 *$ & $2.74 \pm 1.00 * *$ & $2.19 \pm 0.18^{* *}$ & $2.22 \pm 0.10^{* *}$ \\
\hline Chrysin & $1.62 \pm 0.07$ & $1.24 \pm 0.20 *$ & $1.32 \pm 0.20 *$ & $1.17 \pm 0.10 * *$ & $1.17 \pm 0.10^{* *}$ \\
\hline
\end{tabular}

$* p<0.05$ versus no irradiation $(0) ; * * p<0.01$ versus no irradiation $(0)$.

UVA+UVB and preselected polyphenols toward adaptive inflammatory and metabolic responses. Resveratrol was used as a negative control because we have shown previously that resveratrol exerted synergy with UVA+UVB in the induction of definite inflammatory and metabolic responses of NHEK. ${ }^{24,25}$ A 20-minute exposure to this very low-dose UVA+UVB led to phosphorylation of P65, an active unit of $\mathrm{NF} \kappa \mathrm{B}$, a nuclear factor regulating adaptive inflammatory responses to UV irradiation and other pro-inflammatory signals $^{20,23}$ (Fig. 4A). Not surprisingly, both stilbenes resveratrol and its glycosylated derivative polydatin enhanced the
UV-induced phosphorylation, rutin did not affect, while quercetin, verbascoside, and catechin significantly suppressed P65 phosphorylation.

The expression of early pro-inflammatory cytokines, $T N F \alpha, I L 1 \beta, I L 6, I L 8$, and metabolic enzymes CYPIA1 and $C Y P 1 B 1$ at the transcriptional level was sharply upregulated by UVA+UVB at 6 hours postirradiation (Fig. 4B). Resveratrol further increased expression of IL8 and both metabolic genes; however, it suppressed significantly mRNA of genes $T N F \alpha, I L 1 \beta$, and IL6. Quercetin>Verbascoside $>$ Rutin were suppressive for all the genes studied.

Table 3. Cyto-Photoprotection by Benzophenone-3 and Plant Polyphenols Closely Relates to Their Sunscreen Properties Determined In Vitro by Spectrophotometry

\begin{tabular}{|c|c|c|c|c|c|}
\hline \multirow{3}{*}{$\begin{array}{l}\text { Experimental } \\
\text { conditions }\end{array}$} & \multirow{3}{*}{$\begin{array}{c}\text { Viable } \\
\text { cells }(\%)\end{array}$} & \multicolumn{4}{|c|}{ Physical and biological protection (\%) calculated from: } \\
\hline & & \multirow{2}{*}{$\begin{array}{l}\text { Cytotoxicity } \\
\text { experiments }\end{array}$} & \multicolumn{3}{|c|}{$U V$ transmission $(\%)$} \\
\hline & & & $U V A+U V B 290-400 \mathrm{~nm}$ & UVB $290-320 \mathrm{~nm}$ & UVA $320-400 \mathrm{~nm}$ \\
\hline Control cells & $100 \pm 8$ & & & & \\
\hline$+\mathrm{UV}$ & $56 \pm 6 *$ & & & & \\
\hline +UV +Benzophenone & $65 \pm 5 * *$ & $20 \pm 5$ & 20 & 35 & 14 \\
\hline$+\mathrm{UV}+$ Silibinin & $69 \pm 5 * *$ & $30 \pm 5$ & 32 & 47 & 25 \\
\hline +UV +Taxifolin & $68 \pm 6 * *$ & $27 \pm 5$ & 23 & 35 & 18 \\
\hline$+\mathrm{UV}+$ Rutin & $72 \pm 8 * *$ & $37 \pm 6$ & 41 & 37 & 43 \\
\hline +UV +Baicalein & $75 \pm 6 * * *$ & $43 \pm 5$ & 35 & 32 & 36 \\
\hline +UV + Verbascoside & $81 \pm 7 * * *$ & $56 \pm 6$ & 40 & 52 & 35 \\
\hline
\end{tabular}

Immortalized human keratinocyte line (HaCaT) was irradiated by high dose UVA+UVB (UVA $6.0 \mathrm{~J} / \mathrm{cm}^{2}+\mathrm{UVB} 3 \mathrm{~J} / \mathrm{cm}^{2}$ ) for $30 \mathrm{minutes}$ in the total dose $9 \mathrm{~J} / \mathrm{cm}^{2}$ in the absence or presence of $50 \mu \mathrm{M}$ polyphenols. Polyphenols were dissolved in culture medium, thickness of which above cell monolayer was $4 \mathrm{~mm}$. Viable keratinocytes were counted 24 hours postirradiation and incubation in a fresh polyphenoland serum-free medium. Protection in $\mathrm{CP}$ was calculated by the following equation: $\mathrm{CP} \%=\left(\mathrm{V}_{\mathrm{UV}+\mathrm{PP}}-\mathrm{V}_{\mathrm{UV}}\right) /\left(\mathrm{V}_{\text {control }}-\mathrm{V}_{\mathrm{UV}}\right) \times 100$, where $\mathrm{V}_{\text {control }}$ is cell viability in the control cultures, $\mathrm{V}_{\mathrm{UV}}$ is cell viability in UV irradiated cultures, and $\mathrm{V}_{\mathrm{UV}+\mathrm{PP}}$ is cell viability in cells irradiated in the presence of polyphenols. Results are expressed as mean \pm SD of 16 measurements in four independent experiments.

$* p<0.05$ versus Control.

$* * p<0.05$ versus UV.

$* * * p<0.001$ versus UV.

$\mathrm{CP}$, cytotoxicity experiments. 

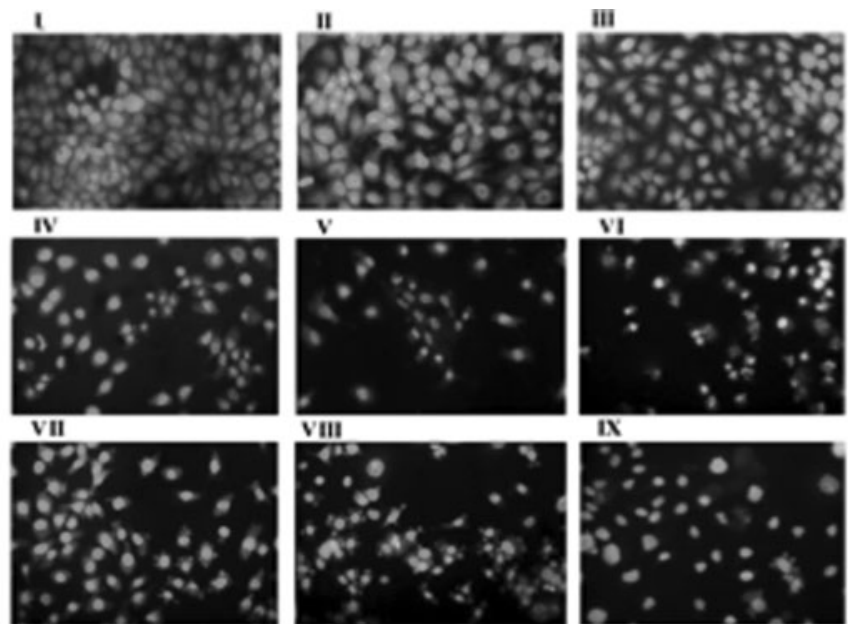

B

\begin{tabular}{|l|c|c|}
\hline \multirow{2}{*}{ Experimental conditions } & \multicolumn{2}{|c|}{$\begin{array}{c}\text { Photo-cytotoxicity } \\
\text { Chemophoto-cytotoxicity }\end{array}$} \\
\cline { 2 - 3 } & \multicolumn{2}{|c|}{ Cell viability (\% of control) } \\
\hline Control & $100 \pm 6$ & $100 \pm 6$ \\
UV & $97 \pm 7$ & - \\
+ Taxifolin, $50 \mu \mathrm{M}$ & $93 \pm 8$ & $\mathrm{ND}$ \\
+ Rutin, $50 \mu \mathrm{M}$ & $97 \pm 7$ & $\mathrm{ND}$ \\
+ + Silibinin, $50 \mu \mathrm{M}$ & $95 \pm 5$ & $\mathrm{ND}$ \\
+ + Verbascoside, $50 \mu \mathrm{M}$ & $94 \pm 6$ & $\mathrm{ND}$ \\
+ Baicalein, $50 \mu \mathrm{M}$ & $101 \pm 5$ & $\mathrm{ND}$ \\
+ Benzophenone-3, $50 \mu \mathrm{M}$ & $85 \pm 8^{*}$ & $94 \pm 8$ \\
+ Ferulic acid, $50 \mu \mathrm{M}$ & $84 \pm 6^{*}$ & $99 \pm 7$ \\
+ Quercetin, $50 \mu \mathrm{M}$ & $78 \pm 8^{*}$ & $98 \pm 6$ \\
+ Cianidin chloride, $50 \mu \mathrm{M}$ & $54 \pm 9^{* *}$ & $101 \pm 6$ \\
+ Resveratrol, $50 \mu \mathrm{M}$ & $27 \pm 5^{* * *}$ & $88 \pm 9$ \\
+ Chalcone, $50 \mu \mathrm{M}$ & $27 \pm 5^{* * *}$ & $75 \pm 7^{* *}$ \\
\hline
\end{tabular}

FIG. 3. Cytotoxicity versus photo-cytotoxicity of polyphenols. (A) Fluorescence photographs of HaCaT cells stained with acridine orange/ethidium bromide: I, control cells; II-III, cells 3 and 6 hours postirradiation (low-dose noncytotoxic $\mathrm{UVA}+\mathrm{UVB}=2+4 \mathrm{~J} / \mathrm{cm}^{2}$ for 40 minutes), respectively; IV-VI, cells similarly irradiated in the presence of $50 \mu \mathrm{M}$ chalcone 3,6 , and 24 hours postirradiation, respectively; VII-IX, cells similarly irradiated in the presence of $50 \mu \mathrm{M}$ resveratrol 3, 6, and 24 hours postirradiation, respectively. (B) For cytotoxicity determination, HaCaT cells were incubated with $50 \mu \mathrm{M}$ polyphenols for 40 minutes. Cell viability was determined by a PrestoBlue viability assay 24 hours postincubation in a polyphenol- and serum-free medium in accordance with Materials and Methods section description. For photo-cytotoxicity determination, HaCaT cells were irradiated by low-dose UVA+UVB $\left(2+4 \mathrm{~J} / \mathrm{cm}^{2}\right)$ in the absence or presence of $50 \mu \mathrm{M}$ polyphenols for 40 minutes. Cell viability was determined by a PrestoBlue viability assay 24 hours postirradiation and incubation in a polyphenol- and serum-free medium. Results are expressed as mean \pm SD of eight measurements in two independent experiments. $* p<0.05$; ** $p<0.01$; ***p $<0.001$ versus UV or Control. ND, not done. 


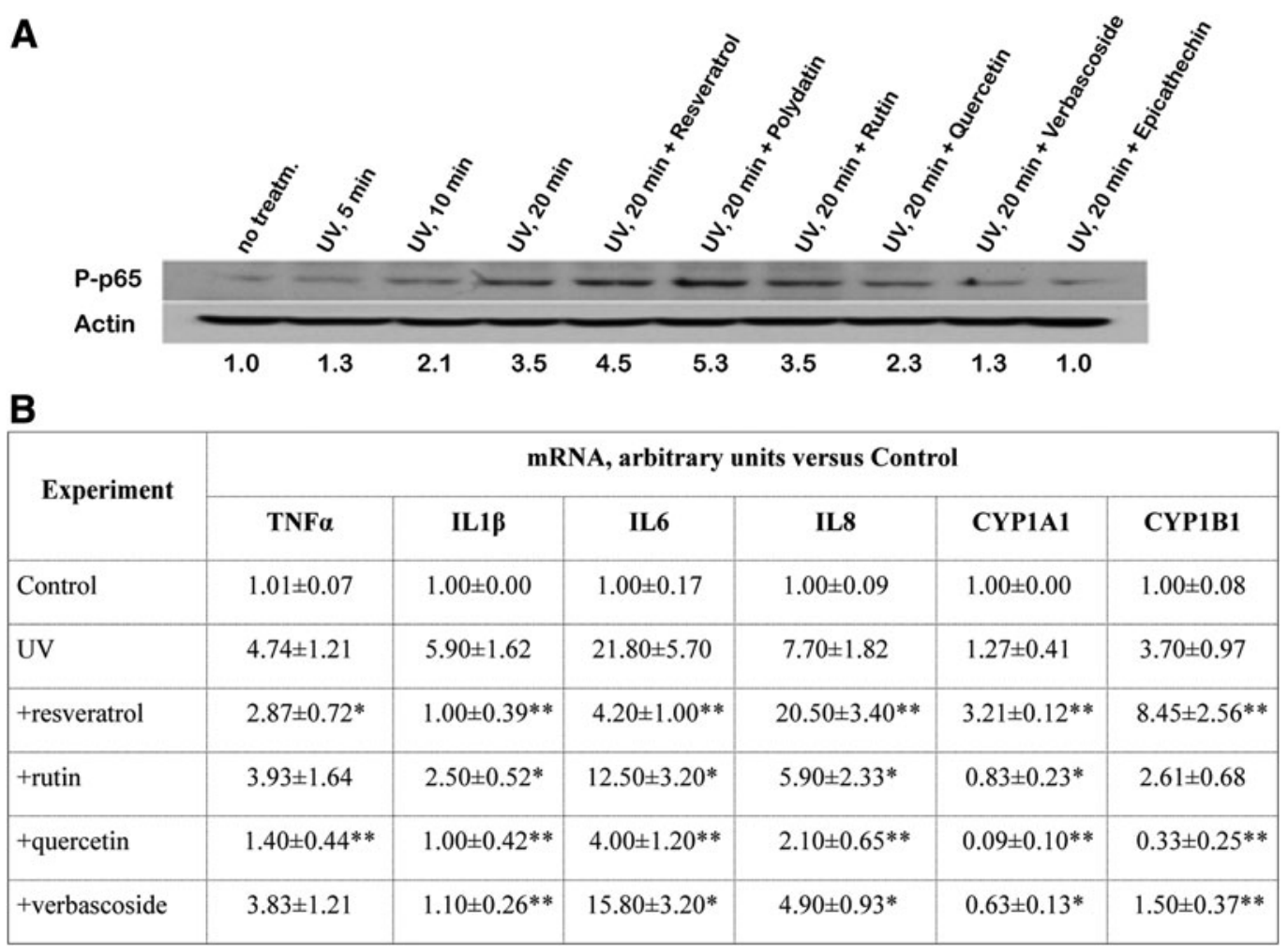

FIG. 4. Effects of polyphenols on (UVA+UVB)-induced inflammatory and metabolic responses of primary human keratinocytes. (A) NF $\kappa$ B activation (measured by Western blot of phosphorylated form of p65, P-p65) in normal human epidermal keratinocytes by UVA+UVB (UVA $1.0 \mathrm{~J} / \mathrm{cm}^{2}+\mathrm{UVB} 0.1 \mathrm{~J} / \mathrm{cm}^{2}$ ) alone or in combination with $10 \mu \mathrm{M}$ polyphenols (resveratrol, polydatin, rutin, quercetin, verbascoside, and epicatechin). Exposure time with UVA+UVB was 5, 10 , and 20 minutes. Exposure to a combination of UV+polyphenol was 20 minutes. Actin was used in Western blots as a control for the protein loading. Quantification of P-p65 was done by densitometry, and data are shown at the bottom of blots. (B) mRNA induction of inflammatory cytokines (TNF $\alpha$, IL1 $\beta$, IL6, and IL8) and cytochrome P450 subfamilies (CYP1A1 and CYP1B1) by UVA+UVB (UVA $1.0 \mathrm{~J} / \mathrm{cm}^{2}+\mathrm{UVB} 0.1 \mathrm{~J} / \mathrm{cm}^{2}$ ) alone or in combination with $10 \mu \mathrm{M}$ polyphenols in normal human epidermal keratinocytes. Real-time PCR analysis was carried out 6 hours postirradiation. Results are expressed as mean values and standard deviation from the mean $(\mathrm{m} \pm \mathrm{SD})$ from nine measurements in three independent experiments. Control values are assumed as $1 .{ }^{*} p<0.05$; $* p<0.01$; versus UV irradiation in the absence of polyphenols.

\section{Discussion}

Protective properties of secondary plant metabolites against solar light of broad spectral range from UV irradiation to visible and infrared light ${ }^{4,6}$ are greatly similar for plant and mammalian cells. This possibility of universal defense is provided by peculiar chemical structure (chromophores) that allows to absorb solar light energy and dissipate it either in the form of thermal or fluorescent/ phosphorescent light energy (sunscreen properties) or convert it into energy for chemical reactions (photosensitizing properties). In this study, we preselected plant polyphenols, mainly with phenylpropanoid, flavonoid, stilbene, and catechin chemical structures, based on several grounds: (1) biosynthesis of these secondary metabolites through phenylpropanoid pathway is rapidly upregulated in plants/plant cells upon exposure to solar irradiation ${ }^{4,6,20}$; (2) plant/plant cell protection against damage related to solar UV irradiation is correlated with enhanced levels of phenylpropanoids, their glycosylated derivatives, and flavonoids ${ }^{6}$; and (3) chemical structures of preselected secondary metabolites are not nitrogen-containing heterocycles, which mostly belong to photosensitizers hence promote type I or II photochemical reactions. The great majority of preselected plant polyphenols were much more or equally effective in UVB screening as benzophenone-3, a golden standard for providing an SPF-B protection (Table 1). A few of them, catechin, in particular, did not effectively absorb UVB. It seems that biological protection from UVB light demonstrated for green tea catechins in a number of publications ${ }^{13,15,21}$ could be mainly attributed to their capacity as free radical scavengers and antioxidants. ${ }^{18}$ Another, indirect although, confirmation of this assumption was obtained in our experiments with the effects of polyphenols on P65 phosphorylation induced by UVA+UVB exposure (Fig. 4). In this case, catechin was extremely effective inhibitor of $\mathrm{NF} \kappa \mathrm{B}$ activation, a classical redox-dependent process. It is worthwhile to underline that many of polyphenols studied were more effective than benzophenone-3 in screening UVA light as well (Table 1). Usually, to achieve an optimal composition of topical sunscreens labeled as products with high broadband UVA+UVB protection, several synthetic molecules having polyphenolic nature-inspired moieties (derivatives of benzoic or cinnamic acids) are combined. ${ }^{8,9}$ To meet requirements of regulatory bodies for claimed SPF-B and SPF-A values, these synthetic substances should be added to sunscreen cosmetics/drugs in 
high concentrations ranging from $10 \%$ to $25 \%{ }^{9}$ that sharply increase risks of adverse cutaneous reactions to polyaromatic synthetics ${ }^{20}$ and might have negative environmental impact. There have been the very first attempts to substitute synthetic sunscreens with the natural ones, for example, leaf extracts of Baccharis antioquensis containing quercetin, kaempferol, and caffeic acid glycosides. ${ }^{31}$ In this study, we observed that capacity of different polyphenols to physical absorption of UVB+UVA light (screening effect) closely related to protection of HaCaT cells from UV-induced cell death (Table 3). To our astonishment, similar molar concentrations $(50 \mu \mathrm{M})$ of benzophenone-3 and plant polyphenols, such as verbascoside and baicalein, in the cultural medium layer over Petri dish bottom, where cellular monolayer was attached, had strikingly different transmission of UVA+UVB and protection against cellular death. Benzophenone-3 absorption/protection was $\sim 20 \%$ and polyphenol-related broadband absorption ranged $35 \%-40 \%$, while protection was between $43 \%$ and $56 \%$. On these grounds, we assume that benzophenone-3 protected cells exclusively by UV screening. In contrast, baicalein and verbascoside protected cell viability through multiple pathways: partly by physical UVA+UVB absorption, partly by direct free radical scavenging (chemical protection), ${ }^{23}$ and/or targeting adaptive/pro-survival such as Nrf2connected pathways in keratinocytes (biological protection). ${ }^{20}$

Previous studies have shown that synthetic sunscreens lost significant part of their protection when exposed to UV irradiation. ${ }^{32,33}$ Unfortunately, natural UVA+UVB screens could also be susceptible to photodegradation mainly by the UVA range. In our experiments, some of them, for example, chalcone and resveratrol, happened to be highly unstable and were subjected to fast UV-induced decomposition, so that their initial SPF-B and UVA protection were sharply (sometimes by more than $60 \%$ ) decreased upon a 1-minute long exposure to solar simulating UV light. Several other compounds were less susceptible for photodestruction and their SPF declined slower (benzophenone-3, chrysin, acacetin, and trans-ferulic and leontopodic acid); the others were stable to UV and their spectral parameters did not change for at least 40 minutes of continuous exposure to UVA+UVB (taxifolin, catechin, verbascoside, and baicalein) (Table 2). The problem of photostability of sunscreens has been drawing close attention since quite some time ${ }^{32,33}$ because it might seriously affect desired durable photoprotection and recommendations regarding frequency of reapplications. The spectral changes observed for highly unstable resveratrol (Fig. 2) allowed us to confirm our previous hypothesis ${ }^{25}$ that the polyphenol having stilbene structure readily reacts with UV irradiation that results in photooxidative modification(s) of its molecule. Products of resveratrol photodestruction cause delayed biological reactions. Chalcone showed similar photo-instability and could be suspected as a cause of similar biological consequences. Of note, chalcone and resveratrol are produced in plant cells through the same phenylpropanoid pathway and they are very close neighbors-metabolites formed at the initial steps of the metabolic rout. ${ }^{10,20}$

Another great concern regarding sunscreen substances is their confirmed/alleged phototoxicity and negative impact to living environment. For example, due to their inherent and combinatory nature with organic matter phototoxicity, titanium dioxide nanoparticles as a physical sunscreen are be- coming a steadily growing environmental and health safety concern. ${ }^{34}$ Photo-chemotoxic properties of benzophenone-3 and preselected plant polyphenols were evaluated in vitro on HaCaT cells exposed to low noncytotoxic dose of UVA+UVB (Fig. 3). Of note, several polyphenols with high broadband sunscreen capacity (ferulic acid, quercetin, and resveratrol) exerted cytotoxicity exclusively after exposure to UV. The same substances were easily destroyed by UV light (Fig. 2 and Table 2). On these grounds, we assumed that photometabolites of the parent polyphenols or/and byproducts of their photooxidation (singlet oxygen, superoxide radicals, or $\mathrm{H}_{2} \mathrm{O}_{2}$ ) could cause irreversible cellular damage so they are not advisable as sunscreens.

\section{Conclusions}

In this study, we proposed a panel of the in vitro methods for preselection of natural photoprotective substances with high photostability and low phototoxicity able of absorbing a broadband UVA+UVB irradiation (physical sunscreen), reducing UV-related overproduction of free radicals and loss of endogenous antioxidants (chemical protection), and attenuating UV-induced cytotoxicity and immune and metabolic responses (biological protection) in primary human epidermal keratinocytes and immortalized human keratinocyte cultures. This allowed us to identify several photostable and nonphototoxic substances, mainly glycosylated phenylpropanoids and flavonoids, with effective broadband physical, chemical, and biological UVA+UVB protection. Verbascoside and leontopodic acids produced by plant cell cultures elicited by UV are promising anti-photoaging actives. The entirely "natural" approach to prevent photoaging and UV-related skin pathologies could diminish negative impact of synthetic sunscreens toward human health and environment.

\section{Acknowledgments}

The authors are grateful to the owners and shareholders of MEDENA AG for covering the cost of the reagents. The authors also express their deep gratitude to Dr. Roberto Dal Toso for the kind gift of verbascoside and leontopodic acids.

\section{Authors' Contributions}

V.K. defined study design, supervised experiments, evaluated the data obtained, and prepared chemical formulas as illustrations. A.P. and A.R.A. performed experiments and did primary statistical calculations. W.M. and C.D. participated in planning of the experiments, in preselecting and purchasing of natural photoprotectors, as well as in the evaluating of the results obtained and conclusion drawing. C.D. did statistical analysis and prepared the illustrations and list of references. L.K. conceived the idea of the study, defined study design, and wrote the article. All the coauthors approved the final version of the article.

\section{Author Disclosure Statement}

W.M. and C.D.L. work for MEDENA AG cosmetic company interested in the research and development of sunscreen and rejuvenate cosmetics. L.K. is engaged as a scientific consultant for MEDENA AG. The other coauthors declare no conflict of commercial interests. 


\section{References}

1. Scharffetter-Kochanek K, Wlaschek M, Brenneisen $P$, Schauen M, Blaudschun R, Wenk J. UV-induced reactive oxygen species in photocarcinogenesis and photoaging. Biol Chem 1997;378:1247-1257.

2. Poon F, Kang S, Chien AL. Mechanisms and treatments of photoaging. Photodermatol Photoimmunol Photomed 2015; 31:65-74.

3. Korkina LG. Phenylpropanoids as naturally occurring antioxidants: From plant defence to human health. Cell Mol Biol (Noisy-le-grand) 2007;53:15-25.

4. Ramakrishna A, Ravishankar GA. Influence of abiotic stress signals on secondary metabolites in plants. Plant Signal Behav 2011;6:1720-1731.

5. Pallela R, Young YN, Kim SW. Anti-photoaging and photoprotective compounds derived from marine organisms. Mar Drugs 2010;8:1189-1202.

6. Frohnmeyer H, Staiger D. Ultraviolet-B radiation-mediated responses in plants. Balancing damage and protection. Plant Physiol 2003;133:1420-1428.

7. Moyal DD, Fourtanier AM. Broad-spectrum sunscreens provide better protection from solar ultraviolet-stimulated radiation and natural sunlight-induced immunosuppression in human beings. J Amer Acad Dermatol 2008;58: S149-S154.

8. Wolf R, Wolf D, Morganti P, Ruocco V. Sunscreens. Clin Dermatol 2001;9:452-459.

9. Commission recommendation of 22 September 2006 on the efficacy of sunscreen products and the claims made relating thereto. Off J Eur Union 2006;265:L39-L43.

10. Dembitsky VM. Astonishing diversity of natural surfactants: 5. Biologically active glycosides of aromatic metabolites. Lipids 2005;40:869-900.

11. Perez-Sancez A, Barrajon-Catalan E, Caturla N, Castillo J, Benavente-Garcia O, Alcaraz M, Micol V. Protective effects of citrus and rosemary extracts on UV-induced damage in skin cell model and human volunteers. J Photochem Photobiol B 2014;136:12-18.

12. Chanchal D, Swarnlata S. Herbal photoprotective formulations and their evaluation. Open Nat Prod J 2009;2: 71-76.

13. Korkina L. Metabolic and redox barriers in the skin exposed to drugs and xenobiotics. Exp Opin Drug Metab Toxicol 2016;12:377-388.

14. Herrmann G, Wlaschek M, Bolsen K, Prenzel K, Goerz G, Scharffetter-Kochanek K. Photosensitisation of uroporphyrin augments the ultraviolet A-induced synthesis of matrix metalloproteinases in human dermal fibroblasts. J Invest Dermatol 1996;107:398-403.

15. Saewan N, Jimtaisong A. Natural products as photoprotection. J Cosmet Dermatol 2015;14:47-63.

16. Korkina L, Mayer W, De Luca C. Meristem plant cells as a sustainable source of redox actives for skin rejuvenation. Biomol, 2017;7:piiE40.

17. Avila Acevedo JG, Espinosa Gonzalez AM, De Maria y Campos DM, Benitez Flores Jdel C, Hernandez Delgado T, Flores Maya S, Campos Conteras J, Munos Lopez JL, Garcia Bores AM. Photoprotection of Buddleja cordata extract against UVB-induced skin damage in SKH-1 hairless mice. BMC Complement Altern Med 2014;14: 281.

18. Martincigh BS, Ollengo MA. The photostabilizing effect of grape seed extract on three common sunscreen absorbers.
Photochem Photobiol 2016 [Epub ahead of print Oct 19]; doi: $10.1111 /$ php. 12652 .

19. Parrado C, Mascaraque M, Gilaberte Y, Juarranz A, Gonzalez S. Fernblock (Polypodium leucotomos extract): Molecular mechanisms and leiotropic effects in light-related skin conditions, photoaging and skin cancers, a review. Int J Mol Sci 2016;17:pii: E1026.

20. Korkina LG, Pastore S, De Luca C, Kostyuk VA. Metabolism of plant polyphenols in the skin: Beneficial versus deleterious effects. Curr Drug Metab 2008;9: 710-729.

21. Potapovich AI, Kostyuk VA, Kostyuk TV, de Luca C, Korkina LG. Effects of pre- and post-treatment with plant polyphenols on human keratinocyte responses to solar UV. Inflamm Res 2013;62:773-780.

22. Pastore S, Lulli D, Potapovich AI, Fidanza P, Kostyuk VA, Dellambra E, De Luca C, Maurelli R, Korkina L. Differential modulation of stress-inflammation responses by plant polyphenols in cultured normal human keratinocytes and immortalized HaCaT cells. J Dermatol Sci 2011;63:104-114.

23. Potapovich AI, Lulli D, Fidanza P, Kostyuk VA, De Luca C, Pastore S, Korkina L. Plant polyphenols differentially modulate inflammatory responses of human keratinocytes by interfering with activation of transcriptional factors $\mathrm{NF} \kappa \mathrm{B}$ and AhR and EGFR-ERK pathways independently of their direct redox properties. Toxicol Appl Pharmacol 2011;255:138-149.

24. Kostyuk V, Potapovich A, Stancato A, De Luca C, Lulli D, Pastore S, Korkina L. Photo-oxidation products of skin surface squalene mediate metabolic and inflammatory responses to solar UV in human keratinocytes. PLoS One 2012;7:e44472.

25. Pastore S, Lulli D, Pascarella A, Maurelli R, Dellambra E, Potapovich A, Kostyuk V, De Luca C, Korkina L. Resveratrol enhances solar UV induced responses in normal human epidermal keratinocytes. Photochem Photobiol 2012;88:1522-1530.

26. Lulli D, Patapovich A, Maurelli L, Dellambra E, Pressi G, Kostyuk V, Dal Toso R, De Luca C, Pastore S, Korkina L. Anti-inflammatory effects of concentrated ethanol extracts of Edelweiss (Leontopodium alpinum Cass.) callus cultures towards human keratinocytes and endothelial cells. Mediators Inflamm 2012;2012:498373.

27. Pastore S, Lulli D, Maurelli R, Dellambra E, De Luca C, Korkina L. Resveratrol induces long-lasting IL-8 expression and peculiar EGFR activation/distribution in human keratinocytes: Mechanisms and implications for skin administration. PLoS One 2013;8:e59632.

28. Sayre RM, Agin PP, Le Vee GJ, Marlowe E. Comparison of in vivo and in vitro testing of sun screening formulas. Photochem Photobiol 1979;29:559-566.

29. Mansur JS, Breder MNR, Mansur MCA, Azulay RD. Determinacao Do Fator De Protecao Solar Por Espectrofotometria. Ann Bras Dermatol Rio De Janeiro 1986; 61:121-124.

30. Livak KJ, SchmittgenTD. Analysis of relative gene expression data using real-time quantitative PCR and the 2(-Delta Delta C(T)) method. Methods 2001;25: 402-408.

31. Mejia-Giraldo JC, Winkler R, Gallardo C, Sanchez-Zapata AM, Puertas-Majia MA. Photoprotective potential of Baccharis antioquensis (Asteraceae) as natural sunscreens. Photochem Photobiol 2016;92:742-752. 
32. Maier H, Schauberger G, Brunnhofer K, Honigsmann H. Change in ultraviolet absorbance of sunscreens by exposure to solar-simulated radiation. J Invest Dermatol 2001;117: 256-262.

33. Marrot L, Belaidi JP, Lejeune F, Maunier JR, Asselineau D, Bernerd F. Photostability of sunscreen products influences the efficiency of protection with regard to UV-induced genotoxic or photoageing-related endpoints. Br J Dermatol 2004;151:1234-1244.

34. Li S, Ma H, Wallis LK, Etterson MA, Riley B, Hoff DJ, Diamond SA. Impact of natural organic matter on particle behaviour and photo toxicity of titanium dioxide nanoparticles. Sci Total Environ 2016;542(Pt A):324-333.
Address correspondence to: Liudmila Korkina

Centre for Innovative Biotechnological Investigations NANOLAB (CIBI-NANOLAB)

Vernadsky Pr. 97/4

Moscow 117437

Russia

E-mail: korkina@cibi-nanolab.com

Received: January 25, 2017

Accepted: June 28, 2017 